\title{
The relationship between planning strategies and entrepreneurial success for start-up entrepreneurs in the Western Cape
}

\section{A psychological approach to entrepreneurship}

\section{Fawzy Basardien, Christian Friedrich and Hamieda Parker}

\begin{abstract}
The total entrepreneurial activity rate in South Africa was $9.1 \%$ in 2011, compared with $8.9 \%$ in 2010, which is below the average for similar economies. This study examines the moderating impact of environmental difficulty on the relationship between planning strategies and entrepreneurial success. The authors carried out a cross-sectional interview-based study of 60 start-up entrepreneurs in the Western Cape in South Africa. The results show that environmental difficulty moderated the relationship of 'opportunistic' and 'reactive' strategies to entrepreneurial success. No moderation effects were found for environmental difficulty on the relationship between success and 'complete planning' and 'critical point planning'strategies.
\end{abstract}

Keywords: entrepreneurial success; planning strategies; strategy process characteristics; environmental difficulty; South Africa

Fawzy Basardien (corresponding author) and Hamieda Parker are with the Graduate School of Business, University of Cape Town, Waterfront Campus, Cape Town, Western Cape 8001, South Africa.E-mail: fawzybasardien@yahoo.com; hamiedap@gsb.uct.ac.za. Christian Friedrich is with the School of Business and Finance, University of the Western Cape, Bellville, Western Cape 8001, South Africa. E-mail: cfriedrich@uwc.ac.za.

The 2011 Global Entrepreneurship Monitor indicates that South Africa's total entrepreneurial activity rate remained constant from $2010(8.9 \%)$ to $2011(9.11 \%)$ (Simrie et al, 2011). This is of serious concern and presents an opportunity for investigation into the factors that impact on entrepreneurial success. Another finding suggests that only a small number of South African start-up businesses grow into mature firms (Kotzé and Smit, 2008). This has negative implications for future sustainable business growth, and for the South African government's growth strategy, particularly as it is expected that small business development could create two-and-a-half million jobs by 2020 (FinMark Trust, 2010).

The National Small Business Act of 1996 (amended in 2004) is aimed at promoting an entrepreneurial climate and making entrepreneurship a priority focal area for job creation and economic development (Department of Trade and Industry, 2008). The policy and strategic framework at national level has resulted in the Provincial Government of the Western Cape implementing numerous support programmes to develop small, medium-sized and micro-enterprises (SMMEs) and to make financial and non-financial support more 
accessible in order to promote a favourable entrepreneurial climate. Against this background, it is imperative to improve the skills base and foster positive entrepreneurial attitudes through education and training. However, without an enabling environment it will be a challenging task to improve the current situation.

Lack of finance has been identified as the primary factor in business failure (Fatoki and Akinwumi, 2010). However, other views suggest that lack of finance can be overemphasized, while other factors, such as entrepreneurial skills and training, are understated (Maas et al, 2008). Hellriegel et al (2008) argue that managerial competencies, such as knowledge, skills, attitudes and personal qualities, are important determinants of successful sustainable entrepreneurship. Due to the fact that entrepreneurship is so complex, the search for distinctive entrepreneurship theories continues as we strive for a better understanding of entrepreneurial success.

This study offers empirical evidence to suggest that high-level planning strategies drive success in difficult environmental conditions and should be included in entrepreneurship research. The study should have significant value to a broad spectrum including government, researchers, financiers, practising entrepreneurs and universities.

\section{Theoretical model}

Entrepreneurship as a theoretical construct and a practical phenomenon remains poorly defined and the interpretation fragmented, suggesting new lines of enquiry (Kikooma, 2010). As an increasing number of psychologists are working in the field, the emphasis on psychological variables has shifted from personality and trait approaches to action-based perspectives, because studies on the former have produced inconsistent results (Foo et al, 2009).

Hence, enquiries using psychological frameworks mark a fresh approach involving a general success model of entrepreneurship that takes into account all psychological variables (Van Gelderen et al, 2007). This approach may be of value to sustainable business development in early-stage entrepreneurship activity as a predictor of entrepreneurial success.

The central model in this study (Figure 1) is a general framework of success based on the main assumption that actions lead to success. The focus is on the planning strategies of the entrepreneur. Strategies have been emphasized as very important to entrepreneurship research, particularly in the context of the growth of global markets, which stimulates competition globally and locally (Muhammad et al, 2010). Entrepreneurial actions have also been studied in pre-start-up, start-up

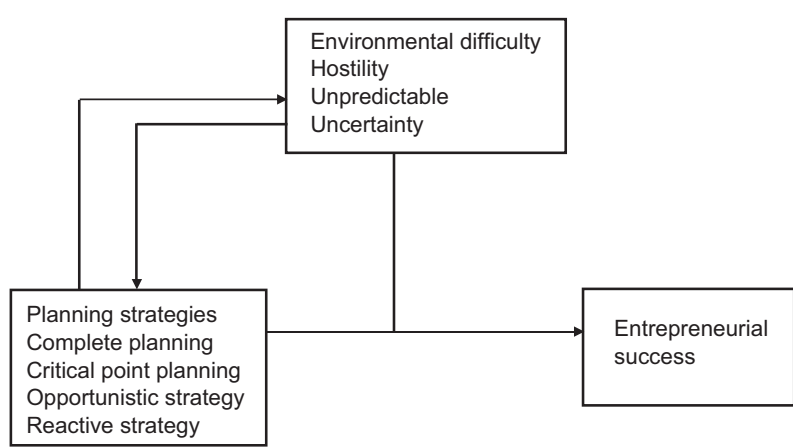

Figure 1. Success model.

and post-start-up phases of successful and unsuccessful enterprises. In such studies, the focus is on how entrepreneurs adapt to changing environmental conditions through learning experiences (Baron and Katz, 2007). Our study focuses on understanding the planning strategies of start-up entrepreneurs in relation to entrepreneurial success under conditions of environmental difficulty.

\section{Strategy process characteristics}

An intense debate has emerged in the entrepreneurship literature on the value of planning, particularly with regard to start-up entrepreneurs. Some scholars argue that formal planning is a vital component in preparing start-up entrepreneurs. One study has shown that of the top 100 business schools in the USA, 78 offer courses on business plan writing (Honig and Karlsson, 2007). Scholars have also pointed out that in many countries business plan competitions play a crucial role in promoting entrepreneurship (Honig and Karlsson, 2007). The question remains, however, as to whether business plan writing skills and the business plan itself can be singled out as a major contributing factor to success. To date there are no consistent empirical studies suggesting that content strategies such as business plans, marketing plans and financial plans are strong predictors of success, particularly for start-up entrepreneurs.

The emergence of new theories concerning entrepreneurial processes in relation to success constitutes a milestone in entrepreneurship research. Strategy process characteristics have provided useful insights into the implementation of general action templates in everyday situations in which individuals discover, evaluate and exploit business opportunities (Gielniek, 2010). In contrast to the study of strategy in the management literature, which focuses on the organizational level, research on strategy process characteristics centres on the individual rather than the organization. The psychological perspective postulates that the individual is the main actor in the business and dominates processes and business decisions. There is no success without action, 
and strategy process characteristics have a direct effect on actions.

Frese's (2000) definition of action strategy distinguishes four areas: complete planning, critical point planning, opportunistic planning and reactive planning strategies. Higher-level planning strategies such as complete planning and critical point planning strategies represent the top-down approach, while lower-level planning strategies such as opportunistic planning and reactive planning strategies represent a bottom-up approach. Higher-level planning strategies also involve long-term planning and high goal orientation, which is translated into commitments of personal (time and effort) and financial resources.

Hypothesis 1: Complete planning and critical point planning are positively related to entrepreneurial success, while opportunistic and reactive planning are negatively related to entrepreneurial success.

\section{Environment}

In line with the view of organizational research, it is expected that the effects of strategy process characteristics on planning strategies will be dependent on the business environment, which has various dimensions uncertainty, the degree of predictability of the environment; complexity, the intricacy of the environment; and hostility, which may emanate from the number of competitors and/or the lack of business opportunities (Gielniek, 2010). A difficult environment is high in uncertainty, hostility and complexity. Such an environment exists when there are many competitors who reduce prices, when it is difficult to predict the future and when many product and process innovations are occurring.

Strategy process characteristics and planning strategies interact with environmental conditions in various ways. Another moderator of the planning-success relationship is the cultural setting in which SMMEs operate. More specifically, the tolerance of uncertainty appears to vary in different cultures (Brinckmann et al, 2010). In South Africa there are many different cultures that may impact on the planning-success relationship. High-level planning strategies such as complete planning and critical point planning strategies should be more effective in difficult environments if entrepreneurs plan well, because planning makes better use of scarce resources and can potentially position the business better.

Hypothesis 1A: Environmental difficulty moderates the relationship between complete planning strategy and entrepreneurial success.

Hypothesis 1B: Environmental difficulty moderates the relationship between critical point planning strategy and entrepreneurial success.
Hypothesis 1C: Environmental difficulty moderates the relationship between opportunistic strategy and entrepreneurial success.

Hypothesis 1D: Environmental difficulty moderates the relationship between reactive strategy and entrepreneurial success.

\section{Methodology}

\section{Research questions}

(1) What is the most preferred type of strategy implemented by the entrepreneur in a difficult environment to ensure success?

(2) What is the least preferred type of strategy in a difficult environment?

(3) What type of strategy is most preferred in an easy environment?

\section{Research context}

The apartheid regime in South Africa prevented black South Africans from owning and starting businesses. This had a major impact on the prevailing level of entrepreneurial activity among black South Africans with its heritage of a lack of entrepreneurial skills, confidence and role models. Black South Africans, especially women, are the least likely to start businesses (Maas and Herrington, 2006). Although there have been numerous government initiatives to support entrepreneurs, the results have not been very successful, especially in relation to start-up entrepreneurs.

Against this background, only start-up businesses were included in the study.

\section{The sample}

All the businesses were based in Cape Town and surrounding business districts and consisted of SMMEs in trade, manufacturing, service and construction sectors. The businesses were randomly selected from the Western Cape Business Opportunity Forum (WECBOF). SMMEs registered as members of WECBOF typically represent a large proportion of start-up entrepreneurs.

The following selection criteria were used. SMMEs were selected from the WECBOF database. Only SMME owners who had run their business for at least three months but not more than three-and-a-half years were included in the sample. The SMMEs selected had between one and 50 employees. Only formal businesses were included in the study.

Of the entrepreneurs selected, the rejection rate was $32 \%$. In total, 60 entrepreneurs were selected (82\% male and $18 \%$ female). Table 1 presents the statistics of the sample. The industries represented included manufacturing $(15 \%)$, construction (12\%), trade (8\%), services 
Table 1. Interview sample, descriptive statistics $(N=60)$.

\begin{tabular}{lrrr}
\hline Variable & N & $\%$ & M (years) \\
Gender: & & & \\
Male & 49 & 82 & \\
Female & 11 & 18 & \\
Line of business: & 9 & 15 & \\
Manufacturing & 7 & 12 & \\
Construction & 5 & 8 & \\
Trade & 35 & 58 & \\
Services & 4 & 4 & \\
Other & & & \\
Number of employees: & 48 & 80 & \\
1-10 (micro-businesses) & 12 & 20 & \\
> 11 (small businesses) & & & \\
Age of business: & 30 & 50 & \\
<5 years & 30 & 50 & \\
> 5 years & & & \\
Age of entrepreneur: & & & \\
Min = 24 , max = 62 & & & \\
Years of education: & & & \\
Less than grade 12 & 12 & 20 & \\
Grade 12 & 7 & 12 & \\
Diploma & 25 & 42 & \\
Degree & 13 & 22 & \\
Postgraduate & 3 & 4 & \\
\hline
\end{tabular}

(58\%) and other (4\%). Most businesses selected (80\%) were micro-businesses (between 1 and 10 employees) and $20 \%$ were small-scale businesses (more than 10 but fewer than 50). The average age of the businesses was 6.3 , and the average age of the entrepreneurs was 44 .

\section{Interview procedure}

The interview procedure was successfully piloted with a small group of entrepreneurs in South Africa (see Krauss et al, 2005; Gielniek, 2010; Basardien, 2012) and was modified and adapted to make it appropriate for the South African context. Structured interviews were employed, both in the sense of a structured script for the interview and a structured analytical scheme to code the answers, plus an interviewer evaluation. The interviews were in English and were not recorded because of the noise level at certain sites. The interviewer wrote down the answers as close to verbatim as possible. Immediately following the interview, the interviewer completed an interviewer evaluation questionnaire, which assessed his or her impressions regarding success factors.

\section{Operationalization of the variables}

The process characteristics consist of complete planning, critical point planning, opportunistic and reactive strategies. These were measured through an extended indepth interview. The respondents were asked to rank a list of common business goals written on cards, and to describe their first and second goals in detail. In this process, the respondents described sub-goals that were related to the cards presented. The sub-goals were repeated and the respondents were asked to describe how they would achieve them. They were also asked what they had already done to achieve these goals. This part of the interview took about 50 minutes.

The responses were coded with the assistance of anchors, such as:

- Complete planning: 'Detailed planning including contingency plans'.

- Critical point planning: 'Only the most important issues are addressed including back-up plans'.

- Opportunistic strategy: 'There is very little planning, the person is easily distracted and is proactive'.

- Reactive strategy: 'There is no planning and the person waits for issues and problems to happen'.

Table 2. Scale characteristics of main variables.

\begin{tabular}{|c|c|c|c|c|c|c|c|}
\hline Scale/index & Number of items & $\alpha$ & M & SD & Range & $\mathbf{N}$ & Inter-rater ${ }^{1}$ \\
\hline Sales success & 3 & 0.72 & 1.34 & 0.91 & $1-5$ & 60 & - \\
\hline Size success & 3 & 0.82 & 2.38 & 0.87 & $1-5$ & 60 & - \\
\hline Growth success & 3 & 0.79 & 3.42 & 1.05 & $1-5$ & 60 & - \\
\hline Entrepreneurial success & 3 & 0.81 & 3.02 & 1.07 & $1-5$ & 60 & - \\
\hline Complete planning & 2 & $(0.83)$ & 1.42 & 0.97 & $1-5$ & 60 & 0.86 \\
\hline Critical point planning & 2 & $(0.87)$ & 1.52 & 1.03 & $1-5$ & 60 & 0.91 \\
\hline Opportunistic strategy & 2 & $(0.86)$ & 3.22 & 0.87 & $1-5$ & 60 & 0.82 \\
\hline Reactive strategy & 2 & $(0.82)$ & 3.67 & 1.24 & $1-5$ & 60 & 0.79 \\
\hline Environment & 8 & 0.78 & 3.38 & 0.63 & $1-5$ & 60 & \\
\hline Gender: $1=$ male, $2=$ female & 1 & - & - & - & - & 60 & \\
\hline Starting capital (Rand) & 1 & - & 29,652 & 97,623 & 0-989,000 & 60 & \\
\hline Age of business (years) & 1 & - & 6.20 & 4.40 & $1-23$ & 60 & \\
\hline Line of business: manufacturing & 1 & - & - & - & $1-2$ & 60 & \\
\hline Line of business: construction & 1 & - & - & - & $1-2$ & 60 & \\
\hline Line of business: service & 1 & - & - & - & $1-2$ & 60 & \\
\hline Line of business: trade & 1 & - & - & - & $1-2$ & 60 & \\
\hline Line of business: other & 1 & - & - & - & $1-2$ & 60 & \\
\hline
\end{tabular}

${ }^{1}$ Intra-class coefficients. 
If there was planning, the coder would assess whether the person planned for one or several issues. Planning for several issues was interpreted as complete planning and planning for one issue as critical point planning. In the case of little or no planning, the degree of proactiveness was assessed. If there was proactiveness, this was coded as an opportunistic strategy. If there was no proactive behaviour and little or no goal-directed behaviour, this was classified as reactive strategy.

With regard to the complexity, hostility and uncertainty of the environment, a five-point Likert scale was used to measure the respondent's perception of his or her environment. The overall scale of environment was 0.78 and the items were $\mathrm{z}$-standardized before they were added to the scale.

Success was also assessed during the interview in terms of growth (increase in clients over the past three years), sales (increase in turnover over the past three years) and size (number of employees). These measures were combined to form an overall scale of entrepreneurial success (see Table 2).

\section{Results}

\section{Direct effects}

Examining the impact of reactive strategy on success, reactive strategy explained $16 \%$ of the variance and was statistically significant $\left(\Delta r^{2}=0.16, p<0.01\right.$; model $4, \beta$ $=-0.40)$. Critical point planning explained $27 \%$ of the variance and was statistically significant $(\Delta r 2=0.27, p$ $<0.01$; model $5, \beta=0.53$ ) and complete planning explained $18 \%(\Delta r 2=0.18, p<0.01$; model $6, \beta=$ 0.48 ). The most significant individual contribution was made by critical point planning (model 5 : $\beta=0.53, p<$ 0.01 ), followed by complete planning (model $6: \beta=$ $0.48, p<0.01$ ). Opportunistic strategy is negatively related to success, but the result is not significant.
Critical point planning strategy characteristics cover fewer business aspects, are less long-term and are less strictly top-down than complete planning strategy characteristics. Thus, entrepreneurs who exhibit critical point planning strategy characteristics develop a less sophisticated mental approach to their entrepreneurial activities and to feedback signals from the environment than entrepreneurs using complete planning strategy characteristics (see Table 3).

Therefore, critical point planning strategy characteristics facilitate a positive business performance development, but not to the same extent as complete planning strategy characteristics. Critical point planning should be the preferred strategy during the start-up phase, when the focus is on fundamental business issues such as raising finance, securing premises and recruiting personnel. Complete planning strategy is best used as the business enters its fifth or sixth year: at this stage, the level of complexities in the business should prompt the entrepreneur to adopt a complete planning strategy.

A reactive strategy indicates a passive approach to external demands and is the least favoured strategy. Previous research confirms a negative relationship between reactive strategy and success (Frese et al, 2002). Opportunistic strategy also has a negative impact on success. However, entrepreneurs adopting such a strategy are able to gain advantages from scanning the environment for opportunities because of their high level of proactive behaviour. On the other hand, their lack of planning and goal orientation can have a negative impact. A low level of planning implies that the entrepreneur will not develop the opportunity fully. Hence, Hypothesis 1 is accepted.

\section{Moderation effects}

Hierarchical regression analyses were used to test Hypotheses 1A, 1B, 1C and 1D. In these analyses the

Table 3. Strategy process characteristics and entrepreneurial success.

\begin{tabular}{|c|c|c|c|c|c|c|}
\hline Variables & Model 1 & Model 2 & Model 3 & Model 4 & Model 5 & Model 6 \\
\hline \multicolumn{7}{|l|}{ Main effects: } \\
\hline Environment & -0.05 & -0.05 & -0.04 & -0.01 & 0.00 & 0.00 \\
\hline Type of industry & & 0.12 & 0.13 & 0.15 & 0.15 & 0.15 \\
\hline \multicolumn{7}{|c|}{ Strategy process characteristics: } \\
\hline Opportunistic & & & -0.02 & -0.04 & 0.03 & 0.05 \\
\hline Reactive & & & & $-0.4^{\star \star}$ & $-0.29^{\star *}$ & $-0.22^{\star *}$ \\
\hline Critical point & & & & & $0.53^{\star \star}$ & $0.30^{\star \star}$ \\
\hline$\Delta R^{2}$ & 0.00 & 0.01 & 0.00 & $0.16^{\star \star}$ & $0.27^{\star *}$ & $0.18^{\text {** }}$ \\
\hline $\mathrm{F}$ & 0.04 & 2.78 & 0.09 & $5.42^{* *}$ & $15.17^{\star *}$ & $21.67^{\star *}$ \\
\hline$P$ & 0.92 & 0.22 & 1 & $0.00^{\star *}$ & $0.00^{\star *}$ & $0.00^{\star *}$ \\
\hline
\end{tabular}

Notes: Controls were reported only if correlated with success in the study $(n=60)$. Standardized coefficients are reported. ${ }^{* *} p<0.01$; *** $p<0.10$. 
Table 4. Moderator effect of environmental difficulty on strategy process characteristics and success.

\begin{tabular}{|c|c|c|c|c|c|}
\hline & Indicator & Size & Sales & Growth & $\begin{array}{l}\text { Entrepreneurial } \\
\text { success }\end{array}$ \\
\hline Complete planning & $\beta$ & 0.22 & $0.12^{*}$ & 0.32 & 0.20 \\
\hline$X$ difficulty & $\Delta R^{2}$ & 0.04 & $0.00^{*}$ & 0.03 & 0.02 \\
\hline$X$ difficulty & $\Delta R^{2}$ & 0.05 & 0.01 & 0.03 & 0.01 \\
\hline Opportunistic strategy & $\mathrm{B}$ & $-0.02^{*}$ & $-0.07^{*}$ & $0.01^{*}$ & $-0.05^{\star}$ \\
\hline$X$ difficulty & $\Delta R^{2}$ & $0.00^{*}$ & $0.01^{*}$ & $0.00^{*}$ & $0.01^{*}$ \\
\hline
\end{tabular}

Note: ${ }^{\star} p<0.10 ;{ }^{* *} p<0.01$.

first step included all the control variables. The second step included the linear component of the predictor (complete planning strategy) and the expected moderator (environmental difficulty). The last step included the product of the predictor and the moderator (Baron and Kenny, 1986). Due to space limitations, the results of the last step of the regression analyses only are reported. Moderator effects were not found for environmental difficulty on all dimensions of success for complete planning strategy. Moderator effects were not found for environmental difficulty for any dimensions of success except for sales success for critical point planning strategy (see Table 4).

Figures 2 and 3 indicate significant moderation effects for environmental difficulty on opportunistic/reactive strategies and entrepreneurial success. No significant effects were found for environmental difficulty on complete planning and critical point planning strategies and entrepreneurial success. Therefore Hypotheses 1A and $1 \mathrm{~B}$ are rejected and Hypotheses $1 \mathrm{C}$ and $1 \mathrm{D}$ are accepted.

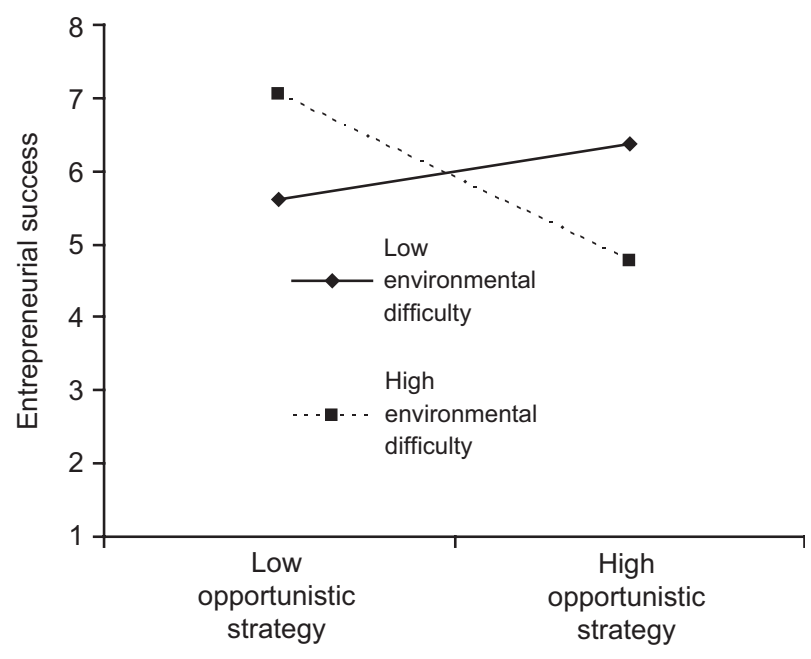

Figure 2. Significant interaction between opportunistic strategy and entrepreneurial success.
The rejection of Hypotheses 1A and 1B suggests that high-level planning strategies such as complete planning and critical point planning should help to ensure entrepreneurial success in a difficult environment. The effects found in relation to Hypothesis $1 \mathrm{C}$ suggest that under difficult environmental conditions an opportunistic strategy is negatively related to entrepreneurial success. When the environmental conditions are easy, there is a positive relationship between opportunistic strategy and entrepreneurial success. The effects found in relation to Hypothesis 1D suggest that, under difficult or easy environmental conditions, a reactive strategy is negatively related to entrepreneurial success. Entrepreneurs using opportunistic and reactive strategies have little or no planning with a low future orientation.

\section{What do these results imply for entrepreneurship in} South Africa?

It is evident that South Africa needs an enabling entrepreneurial environment to realize a significant increase in entrepreneurial activity. Without a more enabling environment, individuals will not see entrepreneurship as a financially viable option. There is also a need to realize growth and success in existing businesses in

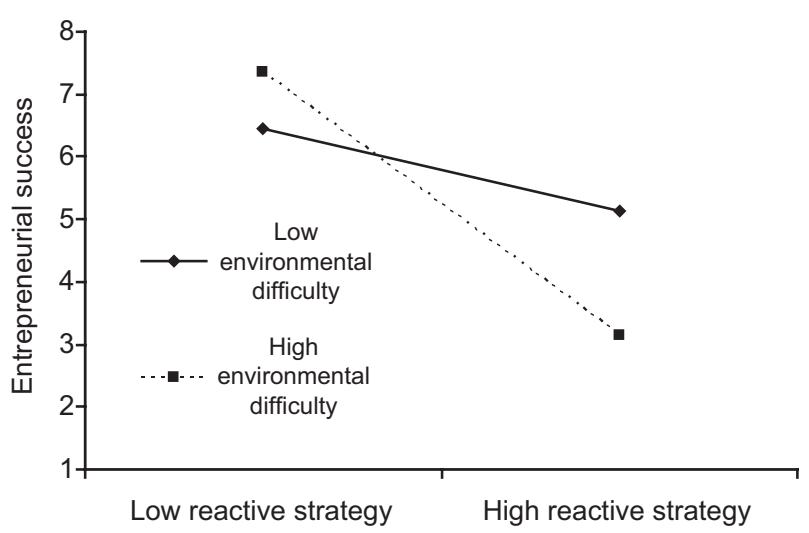

Figure 3. Significant interaction between reactive strategy and entrepreneurial success. 
order to contribute towards a positive entrepreneurial climate, particularly in rural areas.

Studies involving psychological predictors of success and moderating effects are very limited in number. Some previous studies (see Krauss, 2003; Frese and Krauss, 2005; and Frese, 2011) examining the relationship between strategy process characteristics and success have focused on the direct effects through crosssectional and longitudinal research design. Other studies (see Gielniek, 2010) have examined the entrepreneurial process of opportunity discovery, evaluation and exploitation at the start-up phase.

The present study identifies planning strategy as an important function of entrepreneurial success, particularly under difficult environmental conditions. With higher success rates in start-ups, it is possible to create more sustainable job opportunities and to reduce the failure rate of start-up enterprises. In past studies, trait and personality variables, such as locus of control, risktaking propensity and the need for achievement, have been used as predictors of start-up enterprises. Personality traits are persistent and difficult to change. Although many studies have been conducted involving personality traits, there are no consistent results to suggest that such traits can be effectively used to identify the potential characteristics required for entrepreneurial success.

Contemporary approaches involving strategy process characteristics and planning strategies suggest that such process characteristics are, on the contrary, susceptible to change and that it is possible for individuals to acquire the ability, through appropriate education and training, to move from a low-level planning strategy (reactive and opportunistic) to a high-level planning strategy (complete planning and critical point planning). Our study suggests that, under difficult environment conditions with hostile competition and high degrees of uncertainty and complexity, the use of high-level planning strategies by entrepreneurs is more likely to lead to success. However, in an 'easy' environment, the use of an opportunistic strategy may lead to success, given an abundance of opportunities in the market (for example, niche markets).

The findings reported here provide a useful input for existing and future government-funded entrepreneurship programmes, and may help South Africa to achieve better outcomes in the form of an increase in start-up enterprises and sustainable business growth.

The strategy process characteristics approach has important implications for entrepreneurship education in South Africa, particularly in schools and universities. Traditionally, most entrepreneurship curricula have tended to focus on content strategies (management, financial management, marketing management, human resources management, etc). Strategy process character- istics offer a way of assessing how content strategies such as financial management and other management strategies are formulated and implemented.

With high rates of unemployment in South Africa, young people need to be trained with entrepreneurial skills and values so that they are equipped to start new enterprises. Many South Africans grow up with limited business experience or role models and therefore do not have the confidence to start new enterprises. With the introduction of the strategy process characteristics approach into education and training programmes, management programmes can be improved and better outcomes achieved.

This study also has implications for mentors and coaches, bankers and business consultants. Financiers and bankers usually receive business plans for a start-up business that have been prepared by business consultants and entrepreneurs. Business plans could be enhanced through more elaborate and proactive planning in mentorship and business support programmes. Poorly developed business plans could be viewed in terms of the parameters of success discussed in this paper. With low skill levels and business plans often being developed by consultants, potential funders can judge, in light of the findings of this study, how such plans will be implemented by the individual concerned.

\section{Study limitations}

One problem for any study on business success lies in the success measures used. Five measures of success were used to reflect different aspects of what constitutes business success. However, no truly objective measure of success, such as an exact profit rate, could be determined. This was largely due to the fact that business owners kept their official profit rates low for tax reasons, or owners were simply sensitive about revealing them. Another factor is that owners sometimes fail to keep proper accounts and therefore are not aware of what their exact profit rates are.

As the study is a cross-sectional one, it is difficult to draw causal conclusions. Furthermore, only entrepreneurs in the Western Cape participated. The participants were generally better educated and unemployment is generally lower in the Western Cape than in rural areas. In addition, the findings cannot be generalized to entrepreneurs in other parts of Africa. This presents an opportunity for a longitudinal study to obtain a better measure of causality.

\section{Conclusion}

It is clear that strategy process characteristics should be considered in contemporary entrepreneurship research, 
particularly at the individual level, as most research has centred on the firm level. While the importance of formal planning is acknowledged, practitioners often tend to overemphasize its importance.

Moderation effects present a new contribution to entrepreneurship research and should be introduced into longitudinal studies. More importantly, strategy process characteristics and planning strategies can be learned through training interventions. Although previous findings indicate that the implementation of formal planning can lead to improved performance in uncertain conditions, the results are inconsistent. We argue that the introduction of psychological concepts such as strategy process characteristics is equally important and offers a new perspective on entrepreneurial decision making and implementation. Complete planning and critical point planning are representative of high-level planning strategies and have been shown to be associated with all dimensions of success, in contrast to the lower-level reactive and opportunistic planning strategies.

Finally, the study demonstrates the usefulness of psychological approaches in entrepreneurship research and in obtaining a better understanding of the entrepreneurial process, particularly in relation to success.

\section{References}

Baron, R.A., and Katz, J.A. (2007), 'Entrepreneurship: a process perspective', in The Psychology of Entrepreneurship,

Erlbaum, Mahwah, NJ, pp 19-39.

Baron, R.M., and Kenny, D.A. (1986), 'The moderator-mediator variable distinction in social psychological research conceptual, strategic, and statistical considerations', Journal of Personality and Social Psychology, Vol 51, No 6, pp 11731182.

Basardien, F. (2012), 'The role of action strategies on the implementation of financial management practices of emerging entrepreneurs', unpublished PhD thesis, University of Cape Town.

Brinckmann, J., Grichnik, D., and Kapsa, D. (2010), 'Should entrepreneurs plan or just storm the castle? A meta-analysis on contextual factors impacting the business planningperformance relationship in small firms', Journal of Small Business Venturing, Vol 25, pp 24-40.

Chen, Y., and Ming-Chuan, L. (2010), 'Factors influencing the entrepreneurial attitude of Taiwanese tertiary-level business students', Social Behavior and Personality, Vol 38, No 1, pp $1-12$.

Department of Trade and Industry, Republic of South Africa (2008), 'Annual Report', website: http://www.dti.gov.za/ parliament/dti.pdf.

Fatoki, O., and Akinwumi, A. (2010), 'Which new small and medium enterprises in South Africa have access to bank credit?' International Journal of Business and Management, Vol 5, No 10.

FinMark Trust (2010), 'Fin scope small business survey report', Website: http://www.finmarktrust.org.za (accessed 18 May 2012).
Foo, M.D., Uy, M.A., and Baron, M.A. (2009), 'How do feelings influence effort? An empirical study of entrepreneurs' affect and venture effort', Journal of Applied Psychology, Vol 94, No 4, pp 1086-1094.

Frese, M. (2000), Psychological Approaches to Micro-Enterprises in Africa, Greenwood, Westport, CT.

Frese, M. (2011), 'A critical review of the effects of entrepreneurship training in developing countries', Enterprise Development \& Microfinance, Vol 22, pp 335-353.

Frese, M., Krauss, S.I., and Friedrich, C. (2002), 'Function of sociodemographic factors, psychological strategies, personal initiative, and goal setting for entrepreneurial success', in Frese, M., ed, Success and Failure of Microbusiness Owners in Africa, Quorum Books, Westport, CT, and London, pp 103130.

Frese, M., and Rauch, A. (2007), 'Let's put the person back into entrepreneurship research: a meta-analysis on the relationship between business owners' personality traits, business creation and success', European Journal of Work and Organizational Psychology, Vol 16, No 4, pp 353-385.

Gielniek, M.M. (2010), 'Opportunity identification and exploitation: psychological factors for start-up and success in entrepreneurship', unpublished PhD thesis.

Hellriegel, D., Jackson, S.E., Slocum, J., Staude, G., Amos, T., Klopper, H.P., Louw, L., and Oosthuizen, T. (2008), Management, 2 ed, Oxford University Press, Oxford.

Honig, B., and Karlsson, T. (2007), 'Institutional forces and the written business plan', Journal of Management, Vol 30, No 1, pp 29-48.

Kikooma, J. (2010), 'Rethinking entrepreneurship theory and research practice: an exploration into alternative theoretical perspectives', Makerere Business Journal, Vol 10, No 1, pp 120.

Kotzé, L., and Smit, A. (2008), 'Personal financial literacy and personal debt management: the potential relationship with new venture creation', Southern African Journal of Entrepreneurship and Small Business Management, Vol 1, pp 35-50.

Krauss, S.I. (2003), 'Psychological success factors of small and micro business owners in southern Africa: a longitudinal study', unpublished PhD thesis.

Krauss, S.I., Frese, M., Friedrich, C., and Unger, J.M. (2005), 'Entrepreneurial orientation: a psychological model of success among southern Africa small business owners', European Journal of Work and Organizational Psychology, Vol 14, No 3, pp 315-344.

Maas, G., and Herrington, M. (2006), Global Entrepreneurship Monitor. South African Executive Report, University of Cape Town.

Maas, B., Overmeyer, T., Maas, G., Kew, J., Herrington, M., and Mankayi, S. (2008), Western Cape Status of the Youth Report, Cape Town, UCT Centre for Innovation and Entrepreneurship, Cape Town.

Muhammad, M.Z., Char, A.K., Yasoa, M.R., and Hassan, Z. (2010), 'Small and medium enterprises (SMEs) competing in the global business environment: a case of Malaysia', International Business Research, Vol 3, No 1.

Simrie, M., Herrington, D., Kew, J., and Turton, N. (2011), Global Entrepreneurship Monitor 2011. South African Report, website: http://www.gemconsortium.org/docs/2313/gemsouth-africa-2011-report (accessed September 2012).

Urban, B. (2010), 'Entrepreneurship orientation in a developing country context: juxtapositions with South Africa's Innovation Index', Journal of Developmental Entrepreneurship, Vol 13, No 4, pp 425-443.

Van Gelderen, J.L., De Vries, R.L., Frese, M., and Goutbeek, J.P. (2007), 'Differences in psychological strategies of failed and operational business owners in the Fiji Islands', Journal of Small Business Management, Vol 45, No 3, pp 388-400. 